To refer to or to cite this work, please use the citation to the published version:

Evens, T. \& Berte, K. (2014). Challenges of Digital Innovations: A Set-top Box Based Approach. In J. Bourdon \& C. Méadel (Eds.), Television Audiences Across The World: Deconstructing the Rating Machine (pp. 234-247). Basingstoke: Palgrave Macmillan. 


\title{
Challenges of Digital Innovations: A Set-top Box Based Approach
}

\author{
Tom Evens ${ }^{1}$ and Katrien Berte ${ }^{2}$
}

${ }^{1}$ iMinds-MICT-UGent

${ }^{2}$ Centre for Information on the Media

\section{Introduction}

Needless to say, traditional media markets are currently going through fundamental changes, resulting in new challenges and inspiring crossroads. Partly thanks to the massive breakthrough of the broadband Internet as a distribution highway, the convergence of telecommunications, information technology and media has brought us to an industry state of mind where challenging services are launched, traditional value chains are broken, new value constellations arise and innovative - but often unproven - business models are explored. Compared to other mass media, (commercial) television broadcasting is most affected by these mainly technology-driven developments due to its high dependence on advertising revenues (Doyle, 2002). As new media services — especially online and mobile — allow for personalised and direct response advertising, they are grasping a growing share of advertising resources. In broadcasting, the rise of digital television platforms should be mentioned, as well as the ever-growing success of ad-supported online video services such as YouTube and Hulu. This enduring pressure on advertising revenues has moved broadcasters to rethink strategies for connecting with viewers, which results in multi-screen distribution and a shift towards subscription-based revenue models (Evens, 2010). If advertising is to remain the major funding source for private (as well as for some public) broadcasters in the near future, there is a need for a better understanding of viewer behaviour and innovation in television audience measurement techniques. Better insights into usage patterns should also help broadcasters in developing strategies to effectively deal with the increasing uncertainties arising with the evolving television landscape.

As Buzzard (2002) states, audience measurement lies at the economic heart of the television industry and forms one of the critical assets for the broadcasting industry's future success. The provision of accurate, in-depth and real-time audience data is of crucial importance for maintaining television as the world's largest advertising outlet. Advertising agencies increasingly demand and appreciate precise viewing figures to justify media planning and investment decisions (Berman et al., 2009). For broadcasters, audience ratings are seen as valuable information for targeting general as well as niche audiences, planning programmes and evaluating scheduling strategies. Not only private television companies, but also public service broadcasting institutions profit from accurate audience measurement systems to increase programming's impact on society, maximise public value and evaluate their public assignment (e.g., Webster et al., 2000). Despite its authoritative position as one of the best measurable mass media today, television should bend the challenges that arise from the emergence of new digital broadcasting technology — such as audience fragmentation, ondemand viewing and interactive video consumption, multi-platform viewing, and multitasking 
— into opportunities for audience measurement (Urban, 2008). In this context, it is interesting to see how technological developments are affecting social practices and economic relations within the television audience measurement market.

Indeed, as noted by Napoli (2001b), new technology features will induce radical changes in existing industry practices of audience research and analysis, and will result in a discrepancy between the predicted audience, the measured audience and the actual audience. For a long time, information about the 'predicted audience' for a particular time slot was the base for the pricing of advertising space (Napoli, 2003). As on-demand video consumption is - though modestly - gaining importance as television viewing habits change, the traditional panel measurement techniques will become inadequate for identifying the actual viewing patterns and density rates. Today's measurement systems - mainly based on panel studies that are extrapolated to the total audience - form the basis for the so-called 'measured audience'. Owing to the limited viewer samples in panel studies, which is especially a problem for specific target groups and niche channels, the increasing fragmentation of the audience and on-demand viewing will only enlarge the difference between the extrapolated audience rating and the 'actual audience' base. Therefore, the existing panel studies face their limits. As increasing the size of the monitored panel would be too expensive and rather unviable from an economic perspective, innovations in digital broadcasting are assumed to have the potential to track real-time and accurate audience data and ratings. Therefore, the industry is faced with many challenges for future television audience measurement systems in terms of tracking on-demand and time-shifted video consumption (on all distribution platforms, including mobile and online video services), as well as a reconfiguration of the audience measurement industry value chain. Due to the latter, however, upgrading audience measurement systems may not be that self-evident. Miller (1994, p. 58) argues that 'audience estimates emerge from the actions and interplay of several groups: the measurement companies, their clients, and their respondents' and highlights the 'intrinsic role of social forces in fabricating the audience realities'. Such conflicting interests over the results of the measurement may lead to a certain resistance to implementing new measurement systems that may turn the whole industry upside down. These 'monopolistic tendencies', however, are counterbalanced by the need to adapt measurement techniques to the changing nature of technology. Hence, Bermejo (2009, p. 138) contends that 'this interplay between industry dynamics and methodological challenges [...] allows us to understand the process of audience manufacture'.

The main aim of this chapter is to focus on new economic realities as a result of technological developments and to explore pitfalls and opportunities for a real-time provision of actual audience data and profiles that set-top boxes deliver. In the text, the focus will be on Belgium - although reflections will be made from an international perspective. First, the current state of audience measurement in Belgium is described. In the Belgian case, the traditional television audience measurement system is contested by small broadcasters and challenged by the opportunities that the emergence of digital television and, more specifically, the widespread diffusion of set-top boxes provide. Second, three major challenges for traditional measurement techniques are analysed. This section deals with people's changing 
viewing habits, for example on-demand and time-shifted viewing, the provision of more accurate data by set-top boxes, and the increasing interests of platform operators acting as gatekeepers to access to this data. In the final section, conclusions are made.

\section{Television audience measurement in Belgium}

\section{State of television audience measurement}

In Belgium, the television audience measurement is organised by the Centre for Information on the Media (CIM), which is a joint industry committee (JIC). A JIC should be considered a 'neutral organisation' consisting of public and private broadcasters, advertisers and publicists, forming a committee that puts out to tender a contract with different audience research companies (Bourdon and Méadel, 2011). The CIM was established in 1971 and is currently jointly funded by media companies, media agencies, media sales houses and major advertisers. The CIM's mission is to provide its members with accurate, reliable and standardised information to commercialise their media, offering a single currency to the advertising market. The CIM is quite unique in Europe as it has the sole responsibility of delivering the currency not only to the television sector, but also to all other mass media types, including newspapers, magazines, outdoor, cinema, radio, and websites. Furthermore, the CIM is responsible for all official media audience studies and collects data regarding the newspapers' circulation, broadcasters' ratings and web pages' visitor statistics and profiles. These data then form the basis for media planning and investments in Belgium. Typically, the CIM awards the study contracts to independent research institutes and auditors, following transparent tender procedures. These studies are supervised by a technical committee uniting representatives of all major players in the sector and the permanent staff of the CIM in monthly meetings.

Before 1997, television audience ratings for the southern and northern parts of Belgium were collected by separate institutions: Aspemar for the northern part and Sobemap for the southern part. Since 1997, television audience measurement has been performed by one single institution called Audimetrie. The company, a subsidiary of the leading market research company GfK, is still responsible for audience measurement and panel management. The current contract with GfK will be up for renewal in 2012.

Generally, the 'CIM Television Survey', the official name for television audience measurement in Belgium, consists of two main parts; i.e., the audience survey and time logging. Each day, these data are collected and aggregated in one database, and made accessible through tailored software packs by three specialised subcontractors. The combination of viewer data and time-logging data provides advertisers and media agencies with crucial information on the viewing habits of their target audiences and therefore is the base of planning schedules for advertising campaigns.

As with almost all television audience studies across Western Europe, the CIM survey is based on a panel approach. A representative panel of 1,500 households (equally divided 
across the northern and southern part of the country) is established, generating statistics about approximately 3,500 to 4,000 individual viewers. The study recruits only households (either multiple persons living together or who are married), but does not take into account living communities such as jailhouses, nursing homes, or hospitals. Recruitment typically takes place according to a two-step approach. First, a large-scale establishment survey is used to identify households of interest. This yearly establishment survey is the official CIM media, product and press study, but is also used as a recruitment base for other studies, such as the television study. Individuals are selected based on their socio-demographic characteristics, followed by an analysis of the profiles of their family members. Once a candidate-household has been selected, all household members have to complete a yearly questionnaire, which provides a detailed profile of each member in terms of socio-demographics, technology ownership, consumption patterns, etc. Households cannot be part of the panel for any longer than six years. In order to motivate the panel members, incentives are provided by the panel management. A considerable amount of money is spent in order to guarantee the panel's representativeness. Obviously, the recruitment and the maintenance of such a user panel is a very time- and resource-consuming process. Representativeness is key so that panel rotation and panel efficiency are taken into account.

With each household, a dedicated people meter (i.e., TARiS 500 type) is installed and connected to the fixed television set. The meter registers the viewing patterns (broadcast channels, but also VCR and DVD use, gaming on TV, etc.) of the panel members (after they have signed in via the remote control) every fifteen seconds. Each night, the information collected in the modem is retrieved and sent to GfK over the cable network. This peoplemeter approach allows all subscribed broadcasters to analyse the results in daily reference reports the next morning. These audience data help in analysing viewing patterns, density rates, performance of programming strategies and advertising planning. Thanks to the daily updates, broadcasters can rapidly react and adjust their programme scheduling if needed. Media agencies in their turn can use the daily viewing rates to evaluate and adjust their media purchases for their clients' advertising campaigns.

Time logging refers to the capture of all television footage - both programs as well as advertising - into a central database. It is necessary to assign the audience measurement data to a specific program or spot. Advertisers and media agencies use the time-logging data as a controlling mechanism (made available by analytical software) to verify whether a planned commercial has been broadcast. If not, compensations are paid or free advertising space is offered by the broadcasters. In Belgium, this activity is outsourced by the CIM to Mediaxim. Although time logging is also challenged by technological innovations, the focus of this chapter is on the audience measurement aspect. Time logging will therefore not be discussed further in this chapter. ${ }^{1}$

\footnotetext{
${ }^{1}$ For more information regarding time-logging techniques, we refer the reader to one of the authors' PhD thesis. See Berte, K. (2010) Reclame in een digital medialandschap. Uitdagingen, knelpunten en opportuniteiten voor reclame op interactieve digitale televisie [Advertising in a digital media landscape. Challenges, bottlenecks and opportunities for advertising on interactive digital television]. Unpublished $\mathrm{PhD}$ thesis, Ghent University.
} 
In general, the Belgian television audience measurement is evaluated quite positively by its stakeholders. The current methodology is the result of a year-long cooperation of broadcasting companies, advertisers, media agencies and sales houses. Empirical analysis (based on interviews) has revealed that most stakeholders are satisfied with the existing measurement methods and not eager to fundamentally change them. The television audience measurement system as currently deployed in Belgium (and in most mature media markets across Europe) is considered a very reliable and stable system which has proved its value over the years. The use of this system in many European countries has provided numerous guidelines and valuable best-practice examples to help local JICs overcome critical problems, and has resulted in measurement methods that generate comparable data. Such a standardisation in audience measurement systems thus offers added value in terms of performance benchmarking and cross-country analysis of audience figures. Not only between but also within markets, the stability of the research data provides the stakeholders with several opportunities for analysing historical data and identifying long-term viewing patterns (e.g., by using time series analysis). This consistency of data is a valuable asset in what has generally been considered a rather conservative industry which attracts the majority of advertising expenditures and media attention.

Above all, the stakeholders claim that they are quite happy with the existing standardised methods and are not eager to rupture the current measurement model. Thanks to their large market shares, major broadcasters - especially the public service broadcasting institution which was involved in the foundation of the CIM - have established a powerful position within the management committee over the years, enabling them to preserve their own interests. Additionally, larger private broadcasters might be reluctant to introduce innovative measurement methods because each new measurement approach could have a big impact on market shares and advertising revenues. Lower market shares and density rates may adversely affect tariffs charged for advertisements and, thus, overall turnover. Put simply: not only pragmatic arguments are retarding the introduction of innovative measurement approaches, but also commercial interests are putting pressure to stay with the existing measurement methods.

One of the main problems identified with the current measurement system is the enduring effort to build a representative panel. Today, panel size is limited due to financial constraints. Especially smaller broadcasters which exploit thematic digital-only channels complain about this limited panel size, which may obstruct the validity of their market shares and audience ratings. They argue that the existing methods are done 'for' and 'by' the larger companies and contend that the measurement system provides too little detailed profile information about niche audiences. Small broadcasters benefit less from the well-known 'law of the large numbers', according to which the measured average of the results obtained from a large number of cases is close to the actual figure. Hence, small media companies argue that their mainly niche and often micro-sized target audiences remain under-represented in such panel studies and that their market shares and density ratings are biased by these kinds of viewer 
surveys. Although these concerns may partly disappear once digital television penetration is close to $100 \%$, small broadcasters are fervent supporters of switching to innovative measurement systems. Established broadcasters, on the contrary, prefer to maintain the panel approach. One solution often suggested to solve this problem is increasing the panel size, but this will drive up costs, which is not desired by the stakeholders involved (as the costs charged for television audience measurement studies in Belgium are said to be substantial already). The management of the viewer panel is very time consuming and therefore expensive. Furthermore, increasing panel size also implies extra investments in hardware equipment and installation. As switching to more innovative measurement technology would imply too many commercial risks for all stakeholders, however, there is an industry-wide consensus about the added value of the current methodology and an agreement to slightly optimise the existing system to deal with upcoming challenges.

\section{Challenges for television audience measurement}

\section{Tracking on-demand and time-shifted viewing}

The very nature of broadcasting is challenged by digital innovations that have the potential to disrupt traditional television viewing patterns. As digital broadcasting technology has a return path (high up- and downlink capacity) allowing for more interactive communication, a new way of connecting viewers directly to broadcasters arises, using nothing but the remote control or smartphone (Papathanassopoulos, 2002). For broadcasters, this may create opportunities for new revenue streams such as interactive advertising, and the sale of valueadded content such as videos and games. At the same time, digitisation poses important challenges for the traditional television audience measurement systems. Interactive service applications such as video on demand (VOD) and personal video recorders (PVR) allow users more freedom to compose their personal broadcasting scheme. Before the advent of digital television, people's television consumption was largely shaped by fixed program schedules. With digital television, people record their preferred programs and watch whenever they want. Now that broadcasting is more and more shifting to narrowcasting (see, e.g., Hirst and Harrison, 2007), the user gains control of the viewing process. Since these more individualised viewing practices continue to grow, they will increasingly affect traditional audience measurement systems insofar as the institutions involved in television audience measurement need to come up with technical answers to deal with this tendency towards ondemand, time-shifted and mobile video consumption. If we assume that live television consumption - except for particular genres, such as live shows and sports - is to be replaced by new viewing patterns in the near future, live ratings could drastically decline, leaving broadcasters with less attractive audience figures to sell advertisements to. Therefore, audience measurement systems need to come up with smart methods to monitor on-demand, time-shifted and mobile television usage.

Research on time-shifted viewing shows that viewers normally watch a recorded program very quickly after its live broadcast. A distinction is therefore made between three types of television viewing: (a) 'live viewing', (b) 'near live viewing' (NLV) and (c) 'viewing on the 
same day as live' (VOSDAL). Using the Enhanced Audio Matching (EAM) technique, which allows for recognising programs up to six days after the live broadcast thanks to comparing the broadcaster's audio signal to a reference database, NLV and VOSDAL are added to the audience ratings. As a result, the total amount of people viewing the program the same day as it was broadcast can be extrapolated. These data then become available one day after a given program is broadcast. Regarding time-shifted viewing practices, most audience research organisations in Europe are currently investigating and using this more appropriate technology for monitoring time-shifted television consumption.

Since 2008, various countries (such as the Netherlands) have trialled the EAM technique for dealing with the challenges brought by the usage of digital television services. Also in Belgium, the technology has been experimented with in the past years. During the recent negotiations for a new management contract between the CIM and its subcontractors, the need to measure the impact of time-shifted viewing was stressed. Despite the fact that the impact of time shifting is often overestimated, Belgian broadcasters were already a demanding party for introducing the standardised EAM measurement in 2009. However, the EAM technique was implemented only in 2010. Although technological issues were mainly solved and viewer data were collected, the software companies aggregating all data had difficulties in providing accurate data. Finally, in January 2010, the CIM announced the integration of time-shifted viewing in its measurement system and offered back data from 2009 as well. The currency of the TV study changed from 'live' to 'live +6 ' in 2010. Thanks to the implementation of timeshifted viewing, broadcasters now get insight into the consumption of their programs until six days after their first broadcast.

Although registering time-shifted viewing may be a first but important step forward in bridging the gap between current and future audience measurement systems, and between the measured and actual audience, this technique has several limitations. Despite its benefits in providing data about time-shifting practices, the EAM system still fails to provide information regarding the use of other interactive applications, such as digitext, electronic program guide, walled garden applications, email services and enhanced television applications, leaving aside mobile and online video consumption. While using these kinds of applications, the broadcast stream is usually replaced by a split screen in which the live broadcast stream continues to appear in the (upper right) corner. The audio signal of the live broadcast holds the prominent place and therefore the people meter continues to register this activity as viewing behaviour. This assumption is questionable, as most people focus on the interactive applications rather than on the live stream. At this moment, no traditional people meter registers these interactive applications, nor do portable versions of these meters. Given the spectacularly increased usage of on-demand video consumption in Belgium, questions arise whether and to what extent other viewership information retrieval systems can provide more detailed insight into the existing viewing patterns.

Using accurate set-top box-generated data 
Because of the dissatisfaction with the limitations of the EAM system (in the UK but also in other countries), the Sky Broadcasting Group, the UK-based leading pay-television provider, already launched its own viewer panel using the data generated and collected by the customers' set-top box in 2006. These set-top boxes (including electronic programming guide (EPG) and conditional access systems) function as people meters and register all user actions, including linear and interactive viewing behaviour such as time-shifted viewing, on-demand video consumption and other kinds of interactive applications. In addition, in Belgium, several stakeholders (especially broadcasters and media agencies) increasingly encourage digital platform operators to share their data generated by the set-top box. No doubt, the settop box provides quite a good solution for measuring the usage of interactive applications on digital television platforms (Berte et al., 2010). Through their built-in hard disks, these boxes collect operational information by logging all user actions (e.g., channel choice, zapping time, time-shifted viewing, video-on-demand consumption, EPG usage, etc.). Thanks to the performing return path made available with cable and Internet-protocol television platforms, set-top box data regarding audience viewing patterns are easily transferred to platform operators. These set-top box data consist of a set of log files that were originally created to control the system, but also provide an in-depth insight into the usage of the television screen. However, they require a lot of processing before they can actually be read and used for marketing purposes. To date, only a few deployments of set-top box data-driven audience measurement exist (in Australia, New Zealand, South Africa, South Korea, the US and the UK). In most cases, these data are considered supplementary to the results generated by traditional panel studies and aggregated by large research institutions such as Nielsen and TNS. The set-top box approach varies by country: in some countries, the 'opt-in' principle (by which users need to give permission before their data can be exploited) is used, whereas platform operators in other countries prefer to take into account all digital television subscribers.

Such a set-top box data approach offers obvious advantages compared with the current systems of traditional audience measurement and, in particular, the panel studies. Thanks to the large computing capacity of network operators, it is quite easy to continuously monitor and process the data of all platform subscribers. As a result, the set-top box approach can provide realistic estimations of the 'actual audience' size and reduces the bias from classical panel studies, as they should be more representative of the viewing population. Since the penetration of digital television services is increasing quickly, the user base of these services will become more and more representative of the overall population and hence overcome the problems associated with the panel approach. Instead of an extrapolated reach, set-top box data guarantee a more reliable and accurate measurement of the actual audience for smaller and niche-based television channels, which often complain about the biases caused by the relatively limited viewer panels. As experts expect that, together with audience fragmentation, such niche channels will continue to emerge in the future, the need for a set-top box approach will only become more urgent. Finally, such an approach does not require additional investments in hardware (such as people meters) because digital television viewers regularly own (or rent) a set-top box - except for those free-to-air operators offering unencrypted 
content. The set-top box approach thus overcomes a couple of problems raised with traditional panel measurement systems.

Nevertheless, the set-top box approach also has several pitfalls that should be overcome before it is introduced as an industry standard. To start with, the set-top box collects the data at the household level, whereas panel studies provide constantly updated information (in terms of socio-demographics, lifestyle, media behaviour, etc.) about individual viewers thanks to the regular survey waves. This could be overcome by monitoring a panel of digital television viewers, which could be much larger than classical panels because of the limited investments in additional hardware. Another possible solution could be the introduction of an identification system (pin code) for each viewer so that data can be collected on the level of each individual viewer. Another problem is that set-top boxes register the channels only every sixty seconds, compared with fifteen seconds with the dedicated people meters. As audience measurement data are often used for commercial purposes, this time frame is too wide for evaluating the exposure of traditional thirty-second advertising spots. Contrary to dedicated people meters, operators' set-top boxes do not register whether the viewer's television screen is switched on. As long as the set-top box is active - even if the television screen is switched off - the box continues to register all activities. Since most viewers never switch off their set-top box, the set-top box is assumed to overestimate viewing figures - especially at night - by up to thirty per cent compared with classical panel studies. This shortcoming is quite problematic and the industry needs to come up with a technological answer for this problem. A last challenge - which will be discussed in the next section - is closely related to the changing power relations in the broadcasting field. Since platform operators are eager to provide audience measurement data to all stakeholders and play a central role in this market, this increases the urgency for new value constellations and business models.

\section{Reconfiguring the value chain of audience measurement}

As mentioned earlier, the introduction of new technologies may imply innovative social practices and may reshuffle existing value configurations. The application of set-top boxgenerated audience measurement data systems may allow existing players in the market to expand into new roles (e.g., platforms as a data broker) and the entrance of new players (e.g., aggregators for audience measurement data) into the media ecosystem. All this should intensify competition and should further boost technological innovation to come up with the most optimal and high-performing audience measurement system. However, this increasing uncertainty may also provoke conflicts of interests between several stakeholders in the ecosystem and may therefore slow down innovation in audience measurement technology rather than stimulate it. In the remaining part of this chapter, a couple of important observations and implications for the introduction of an audience measurement model generated by set-top boxes are briefly presented.

Whereas broadcasters were obviously the most important stakeholder in the broadcasting sector for years, recent technological innovations have provoked a tough struggle for platform leadership and customer relationship in the industry (Donders and Evens, 2011). Operating as 
gatekeepers, digital television platforms have positioned themselves in the middle of the broadcasting market while providing consumers with direct access to a wide variety of highquality content. These operators are currently facing increasing competition from online video websites (over the top television [OTT]) to secure their role as the main supplier of content and related services. The audiovisual market is further destabilised by the emergence of IPconnected devices and the growing importance of consumer electronics providers such as Samsung and Sony, which are keen to control access and play a central role in the customer relationship. Hardware manufacturers have launched connected consumer equipment allowing content providers to bypass traditional content aggregators (either provided in a platformcontrolled walled garden or in a more 'open' environment) and to establish a direct-toconsumer relationship. Broadcasters have also established direct access to consumers by developing online on-demand portals and mobile television applications for smartphones and tablet PCs. Additionally, broadcasters have launched second screen applications to interact with viewers on mobile devices and to retrieve all kinds of customer information (including profile data). This struggle for platform leadership is mainly inspired by each of the platforms' aim to create added value by exploiting knowledge of asymmetric information in two-sided markets.

Indeed, several platform operators invest in optimising subscriber data management, since set-top boxes allow for better provision and analysis of audience figures, buying patterns and customer segments. This way, digital television providers would act as a data broker and monetise their existing assets, which would allow the advertising industry to better target and personalise marketing messages (van den Dam and Nelson, 2008). Fearing a new competitor for advertising revenues and becoming dependent on telecom platforms for the provision of data, broadcasters would like to have free and unlimited access to this customer data. Whereas broadcasters argue that their content is driving the diffusion of digital platforms and that these platforms should share all data, platform operators see opportunities for a new revenue stream and for establishing a new industry-wide JIC. This could imply the replacement of traditional audience research institutes by a more operator-centric measurement model. The introduction of set-top box-generated data as the primary means for audience measurement could thus imply a completely disruptive business model for the television audience measurement market. But it is highly uncertain that broadcasters want to step into such a model and give up the controlling position they have at present in television audience measurement systems.

\section{Conclusions}

The aim of this chapter was to provide an overview of industry challenges in television audience measurement as a result of new technology, both from an academic and a more industrial perspective. It has been argued that the real-time provision of actual audience data by means of set-top boxes may help the industry to overcome the challenges related to changing media consumption patterns - in particular, time-shifted and mobile viewing. Although the use of set-top box data still has several pitfalls and more research is certainly needed to adapt the system to the (extensive) technical requirements of the broadcast industry, such a measurement approach holds interesting opportunities for the industry to come up with 
realistic estimations of the actual audience size. However, as it was also argued, technological innovations may challenge existing business models and may provoke conflicts of interests between several stakeholders in the ecosystem. Despite having the opportunities to overcome some major problems associated with traditional user panel studies, the introduction of a settop box-driven model is not warmly welcomed by most industry stakeholders. Most stakeholders plead for an optimisation of the measurement system (including solutions for ondemand and mobile viewing) instead of a complete rupture of the existing system. Rather than a radical alternative to current measurement systems, broadcasters consider set-top box data to be a complement to panel studies. The struggle for platform leadership and, especially, the quest for user-profile data will continue to influence audience measurement systems. Since most stakeholders seem reluctant to adopt a disruptive model, they may stimulate the audience measurement industry to optimise existing rating systems. New innovations in television audience measurement will be taken into account by the industry not only when the new performing technology is providing more accurate estimations of the actual audience, but also - and this condition may weigh more than the previous - when the system is supported by the whole ecosystem. In this regard, television audience measurement systems should be seen as systemic innovations that can be introduced only when there is a strategic fit between the interests of all stakeholders. As long as there are conflicting interests between broadcasters, telecommunication companies, advertisers and audience research institutes regarding the use and implementation of set-top box-generated data, such a system will never develop as an industry-wide television audience measurement model, even though it has important benefits compared with existing audience measurement systems.

\section{References}

Berman, S. J., Battino, B., Shipnuck, L., \& Neus, A. (2009). The End of Advertising as we know it. In D. Gerbarg (Ed.), Television goes Digital (pp. 29-55). New York: Springer.

Bermejo, F. (2009). Audience manufacture in historical perspective: from broadcasting to Google, New Media \& Society, 11(1/2), 133-154.

Berte, K., Leroux, P., Schuurman, D., De Marez, L., De Bens, E. \& De Turck, F. (2010). Challenges and opportunities of iDTV for audience measurement systems: a set-top box based approach, International Journal of Digital Television, 1(2), 221-229.

Bourdon, J. \& Méadel, C. (2011). Inside television audience measurement: deconstructing the ratings machine, Media, Culture \& Society, 33(5), 791-800.

Buzzard, K. S. (2002). The Peoplemeter Wars: A Case Study of Technological Innovations and Diffusion in the Ratings Industry. Journal of Media Economics, 15(4), 273-291.

Donders, K. \& Evens, T. (2011). Cable wars and business battles in broadcasting markets: implications for Internet television, Proceedings of the $26^{\text {th }}$ European Communications Policy Research Conference (EuroCPR) 2009, March 27-29, 2011, Ghent, Belgium.

Doyle, G. (2002). Understanding Media Economics. London: Sage Publications.

Evens, T. (2010). Value networks and changing business models for the digital television industry. Journal of Media Business Studies, 7(4), 41-58.

Hirst, M., \& Harrison, J. (2007). Communication and New Media. From Broadcast to narrowcast. Sidney: Oxford University Press. 
Miller, P. (1994). Made-to-order and Standardized Audiences: Forms of Reality in Audience Measurement. In J. Ettema \& C. Whitney (Eds.), Audiencemaking: How the Media Create the Audience (pp. 57-74).Thousand Oaks: Sage.

Napoli, P. M. (2001b). The Audience Product and the New Media Environment: Implications for the Economics of Media Industries. International Journal on Media Management, 3(2), 66-73.

Napoli, P. M. (2003). Audience Economics. Media Institutions and the audience Marketplace. New York: Columbia University Press.

Papathanassopoulos, S. (2002). European Television in the Digital Age. Cambridge: Blackwell Publishers.

Urban, A. (2008). Changing Business Environment in Digital Television. In A. Urban, B. Sapio \& T. Turck (Eds.), Digital Television Revisited: Linking Users, Markets and Policies. Budapest: COST Action 298.

van den Dam R. \& Nelson E. (2008). How telcos will change advertising. Journal of Telecommunications Management, 1(3), 237-246.

Webster, J. G., Phalen, P. F., \& Lichty, L. W. (2000). Rating Analysis. The Theory and Practice of Audience Research. Mahwah: Lawrence Erlbaum Associates. 